\title{
Yields of rare earths in the process of smelting steels by magnesia crucible
}

\author{
Ya-Bo Li 1,2, a, Ji-Peng Zhao 2,b and Shao-kang Liü, \\ ${ }^{1}$ School of Materials Science and Engineering, Jiangsu University, Zhenjiang, China \\ 2 Tongyu Heavy Industry Co., Ltd., Yucheng, China \\ 3 Jiangsu Yonggang Group Co., Ltd, Zhangjiagang, China \\ awslyb76@163.com, b1476863124@qq.com, Cliushangkang_0203@sina.com
}

\begin{abstract}
Keywords: lanthanum; cerium; magnesia crucible; inclusion; liquid steel
Abstract. Two types of steels containing rare earths (RE) were smelted by the vacuum induction furnace with magnesia crucible, RE metals were added in liquid steel at the end of the smelting process, chemical compositions of the test steels were analyzed, and inclusions were observed by scanning electron microscope with energy dispersive spectrometer. The experimental results show that the yields of RE have no direct relationship with the oxygen and sulphur contents, but decrease with the increasing of RE addition amounts. The reaction between $\mathrm{RE}$ and $\mathrm{MgO}$ (the material of the crucible) is the major RE consumption mode, parts of the outer refractory are peeled off and become inclusions in the test steels. Because of the excessively active chemical properties, rare earths trend to react with refractory materials and metallurgical slag. Therefore, it is very difficult to utilize RE in the industrial production processes with con-casting, adding RE in the non-slag and non-refractory special processes may be feasible.
\end{abstract}

\section{Introduction}

Many beneficial functions of rare earths in ferrous materials were found, such as liquid steel deeply cleaning, inclusions modifying, solidification structure improving, and micro-alloying [1-3]. In recently years, rare earths were used in various steels and made such positive effects as listed: improved the high temperature oxidation resistance of the heat resistant steel and ferritic steels [4, 5]; improved the corrosion resistance of the $\mathrm{Fe}-\mathrm{Cr}$ alloys and other steels [6-12]; improved the mechanical properties of many steels at room temperature and elevated temperature, and benefiting the hot workability [13-21]; modified the microstructures and inclusions in steels [22-26]; and so on. But due to the excessively active chemical properties, RE trend to react with other elements and materials, the yields of RE cannot be controlled prospectively, and the application of RE in steels are commonly restricted to laboratory scale, it has become the main reason of limiting RE's industrial application in steels.

Under the laboratory condition, two methods for adding RE into steels are widely adopted: the one is adding RE into liquid steel in crucible at the end of smelting stage, and the other is hanging RE wire or bar in ingot moulds. The second method can obtain the higher yields, but the RE segregation occurs consequently. In this experiment, two types of steels were smelted by a $50 \mathrm{~kg}$ vacuum induction furnace with magnesia crucible, adopted the first RE adding method, added lanthanum and cerium metals in the liquid steel, yields of RE and inclusions in the steels were researched.

\section{Experimental}

Smelting instrument: $50 \mathrm{~kg}$ vacuum induction furnace (VIM) with $\mathrm{MgO}$ crucible.

Steel grades: shipbuilding hull steels and 00Cr12 ferrite stainless steels with different rare earths contents.

Raw materials: technical pure iron, chromium metal, manganese metal, ferro silicon, ferro phosphorus, aluminium metal, RE metals (about 5 grams per block) and graphite block. 
The smelting process of shipbuilding hull steels is: charging the technical pure iron $\rightarrow$ vacuumizing atmosphere pressure below $15 \mathrm{~Pa} \rightarrow$ power on and begin melting $\rightarrow$ refining after melt-down (keep this vacuum degree more than 15 minutes) $\rightarrow$ filling argon and heating up $\rightarrow$ alloying (add the alloys except lanthanum and aluminium) $\rightarrow$ heating $\rightarrow$ adding the aluminium and lanthanum metal $\rightarrow$ heating up $\rightarrow$ casting into $39 \mathrm{~kg}$ ingots in the vacuum chamber after the lanthanum metal melt-down for one minute.

The smelting process of ferrite stainless steels is: charging technical pure iron and chromium metal $\rightarrow$ vacuumizing atmosphere pressure below $15 \mathrm{~Pa} \rightarrow$ power on and begin melting $\rightarrow$ refining after melt-down (keeping this vacuum degree more than 15 minutes) $\rightarrow$ filling argon and heating up $\rightarrow$ alloying (add the alloy metals except cerium) $\rightarrow$ heating $\rightarrow$ adding the cerium metal $\rightarrow$ heating up $\rightarrow$ casting into $39 \mathrm{~kg}$ ingots in the vacuum chamber after the cerium metal melt-down for one minute.

Normal elements contents were analyzed by inductively coupled plasma-optical emission spectrometry (ICP-OES), RE contents were analyzed by inductively coupled plasma-atomic emission spectrometry (ICP-AES), total oxygen contents were analyzed by oxygen nitrogen analyzer, and inclusions were observed by scanning electron microscope (SEM) with energy disperse spectroscopy (EDS).

\section{Results and discussion}

Chemical compositions of shipbuilding hull steels and yields of lanthanum were listed in Table 1 .

Table 1. Chemical compositions of the shipbuilding hull steels and yields of lanthanum

\begin{tabular}{|c|c|c|c|c|c|}
\hline \multirow{2}{*}{ Sample number } & \multicolumn{3}{|c|}{ Chemical composition (wt \%) } & \multirow{2}{*}{$\begin{array}{l}\text { Lanthanum addition } \\
\text { amount(wt } \%)\end{array}$} & \multirow{2}{*}{$\begin{array}{c}\text { Yield of } \\
\text { Lanthanum(\%) }\end{array}$} \\
\hline & $S$ & $\mathrm{O}$ & $\mathrm{La}$ & & \\
\hline 1 & 0.0027 & 0.0010 & 0.0092 & 0.050 & 18.4 \\
\hline 2 & 0.0042 & 0.0009 & 0.0054 & 0.012 & 45.0 \\
\hline 3 & 0.0020 & 0.0020 & 0.0072 & 0.250 & 2.9 \\
\hline 4 & 0.0063 & 0.0018 & 0.0066 & 0.100 & 6.6 \\
\hline 5 & 0.0042 & 0.0019 & 0.0035 & 0.200 & 1.8 \\
\hline
\end{tabular}

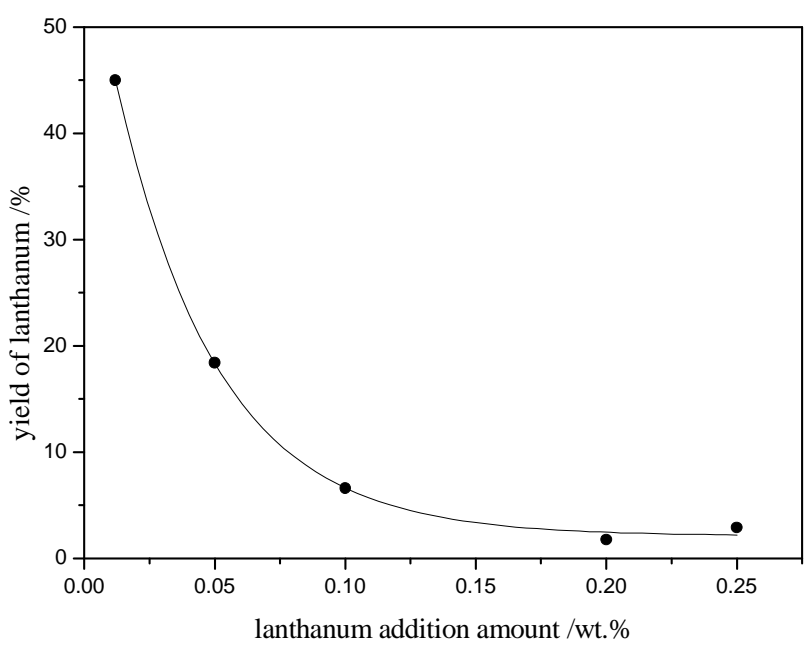

Figure1. Relationship between the yields of lanthanum and the addition amounts

From Table 1, oxygen contents in the steels are controlled under a low level less than 20ppm, and sulphur contents are controlled below 65ppm. The yields of lanthanum decreases along with the increasing of the lanthanum addition amounts as shown in Figure 1, and have no apparent relationship with the oxygen and sulphur contents. The same phenomenon appears again in smelting the $00 \mathrm{Cr} 12$ stainless steels, as shown in Table 2 and Figure 2. 
Table 2. Chemical compositions of the 00Cr12 stainless steels and yields of cerium

\begin{tabular}{ccccccc}
\hline \multirow{2}{*}{ Sample number } & \multicolumn{2}{c}{ Chemical composition (wt \%) } & & $\begin{array}{c}\text { Cerium addition } \\
\text { amount (wt \%) }\end{array}$ & \multicolumn{2}{c}{$\begin{array}{c}\text { Yield of cerium } \\
(\%)\end{array}$} \\
\cline { 2 - 4 } & $\mathrm{S}$ & $\mathrm{O}$ & $\mathrm{Ce}$ & 0.048 & 53.9 & 66.4 \\
7 & 0.0040 & 0.0130 & 0.026 & 0.048 & 38.2 \\
8 & 0.0076 & 0.0110 & 0.032 & 0.094 & 0.094 & 29.7 \\
9 & 0.0040 & 0.0079 & 0.036 & 0.155 & 27.1 \\
10 & 0.0024 & 0.0055 & 0.028 & 0.155 & 11.6 & 18.3 \\
12 & 0.0040 & 0.0100 & 0.042 & 0.317 & 0.317 & 17.7 \\
\hline
\end{tabular}

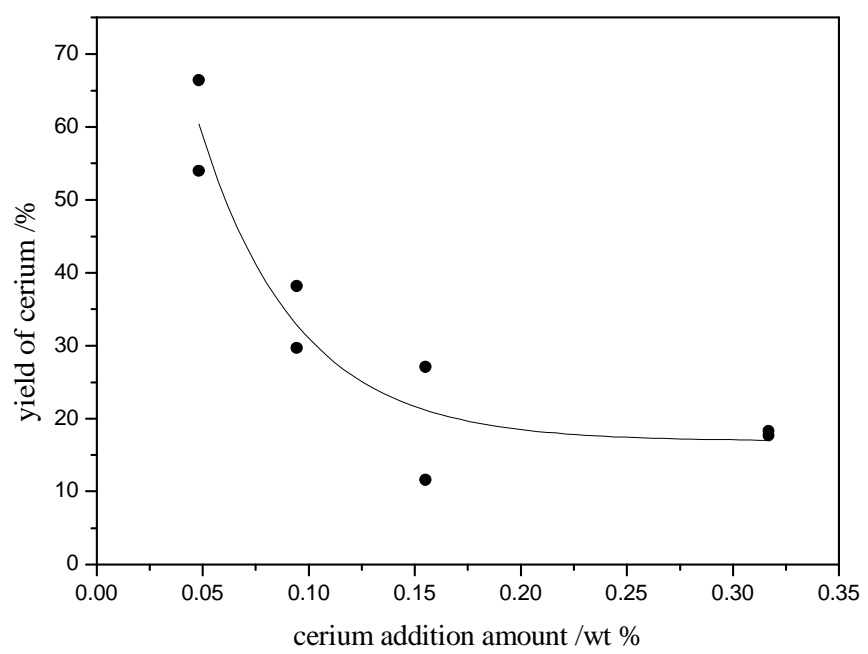

Figure 2. Relationship between the yields of cerium and the addition amounts

Comparing Table 1 with Table 2, cerium shows the higher yield than lanthanum at the same addition level.

Comparing Table 1 with Table 2, cerium shows the higher yield than lanthanum at the same addition level.

Through the past documents, the yields of RE have a close relationship with the oxygen and sulphur contents in steels, the effect of deoxidation and desulphurization in liquid steel played a great role on RE consumption [27]. But in this experiment, the yield of RE has no apparent relationship with the oxygen and sulphur contents, especially during smelting the shipbuilding hull steels, even the oxygen contents are controlled below 20ppm, the yield of lanthanum still remained very low. Smelting and casting are carried out in the vacuum chamber, and the RE metals should not be oxidized by the atmosphere; the deoxidization and desulphurization products of the RE have higher specific gravities closing to liquid steel's, which makes these inclusions cannot be removed easily; boiling points of RE metals are very high, so little amount of RE metals evaporates off from the liquid steel [28]. Because of these reasons above, the yields of RE should to be quite high in this experiment, but the opposite results are obtained, obviously the RE metals are consumed through another path.

Cerium has an excessively active chemical property, can react with the crucible material at the steelmaking temperature as Formula (1) below [29]:

$$
\begin{gathered}
3 \mathrm{MgO}_{(s)}+2 \mathrm{Ce}_{(l)}=3 \mathrm{Mg}_{(g)}+\mathrm{Ce}_{2} \mathrm{O}_{3(s)} \\
\Delta G=(367130-279.53 \mathrm{~T}) \mathrm{J} / \mathrm{mol}
\end{gathered}
$$

At $1600^{\circ} \mathrm{C}$, the Gibbs free energy of the above reaction is -156430 , the reaction can occur spontaneously. Lanthanum has a more active chemical property than cerium and can react with $\mathrm{MgO}$ more easily. 
The lanthanum and cerium metals have lower specific gravities than the liquid steel, so can be melted floating above the liquid steel. When the liquid steel being heating in the VIF, the liquid level appears bow-shaped by the magnetic force, so the RE metal blocks get together and melt down at the edge of liquid steel surface near the side wall of crucible, this phenomenon can be observed through the VIF peephole as drawn in Figure 3.

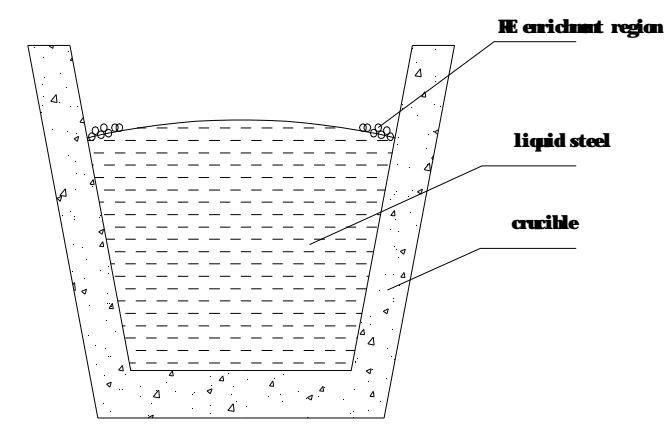

Figure 3. Illustration of RE's melting mode in vacuum induction furnace

Therefore, the molten RE metals react with the crucible material with a very fast rate at the steelmaking temperature. When adding the small amounts, the RE metals should melt down and diffuse into the inner liquid steel very quickly, the effect response area between the liquid RE metals and the crucible is small and the reaction time is short, therefore less amount of the RE metals is wasted and the higher yield can be obtained. On the contrary, the lower yield occurs when adding large amount of RE metals.

Solute RE metals in liquid steel also can react with the crucible, leads to the RE metals consumption either, but being limited by the RE concentration and diffusion rate in the liquid steel, the impact of this consumption mode is smaller than the first one. As mentioned above, the chemical reaction between $\mathrm{RE}$ metals and crucible is the primary reason of the RE metals consumption. In literature [30], isotope experiment results proved such conclusion preferably, the autoradiography picture of magnesia crucible and metal ingot (Figure 4) showed: large amount of RE segregated in the area of the crucible side wall and near the liquid steel surface, which meant large amount RE metal reacted with crucible in this area.

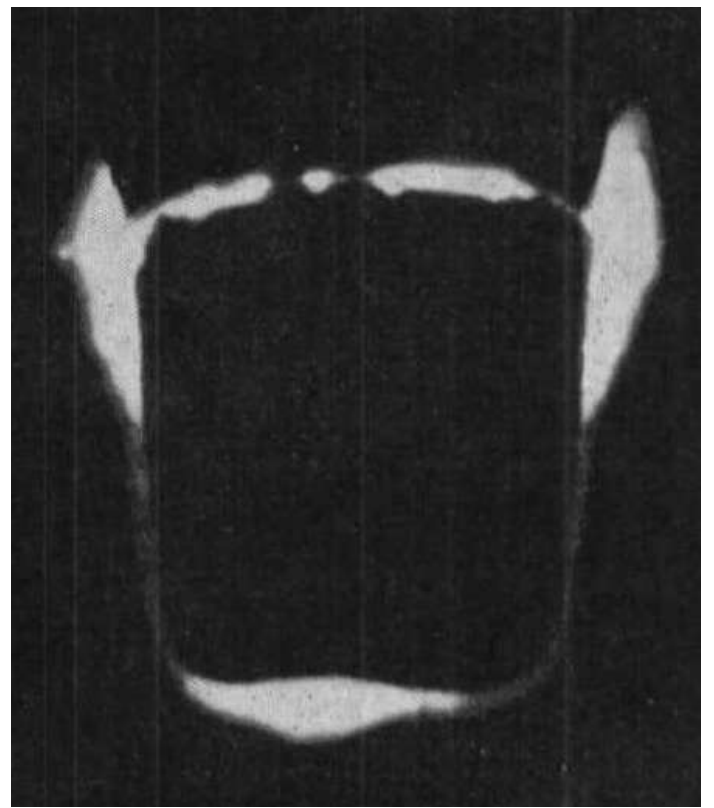

Figure 4. Autoradiography picture of magnesia crucible and metal ingot [30] 
In this experiment, the observation result of the inclusions by SEM also shows: parts of the outer crucible side wall are peeled off because of the RE's erosion, turn into the large scale and irregular shape inclusions, which containing magnesium and cerium as shown in Figure 5.
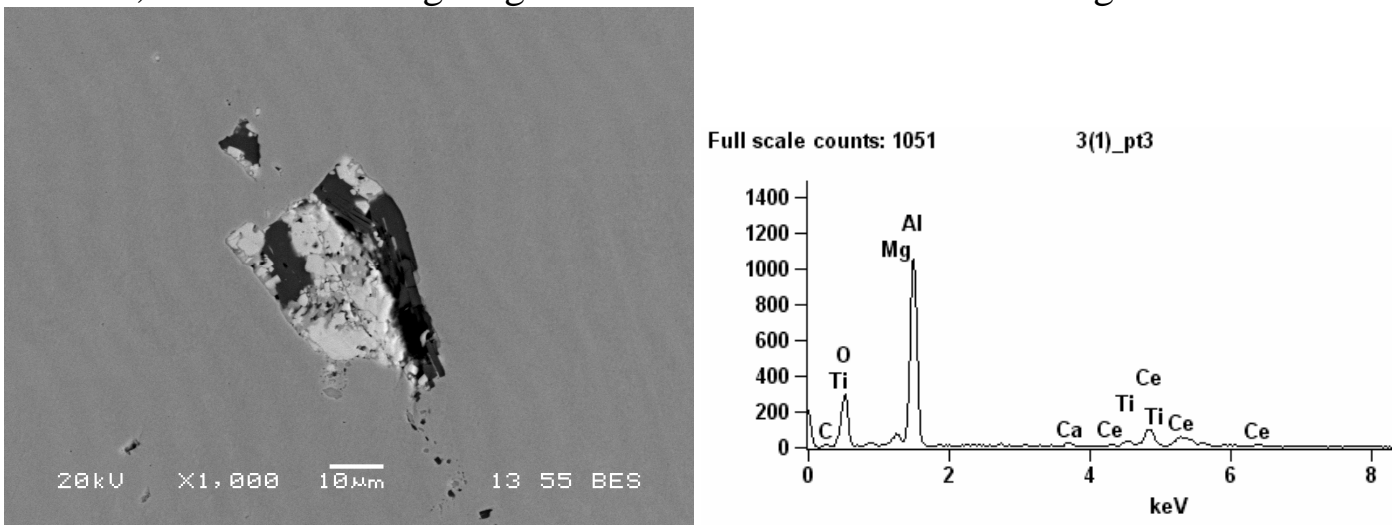

Figure 5. Back scattered electron image and EDS result of the inclusion containing magnesium and cerium

At present, in the industrial production processes, feeding RE metal wire in con-casting mold is commonly used in order to get the higher and stable RE yield. But the practical work shows it is not an ideal method to add RE in steels, for the RE's heterogeneous distribution and making continuous casting mould flux metamorphic, which may carry out product quality problems and even production accident $[31,32]$.

In the industrial production, the magnesia and alumina materials are widely used as the refractory material; $\mathrm{Al} 2 \mathrm{O} 3$ and $\mathrm{SiO} 2$ commonly exist in LF slag, tundish flux and con-casting mold flux. Because of its active chemical properties, the RE elements react with these materials easily, not only affects the yield of RE but also brings other problems, so it is very difficult to smelt the steels containing $\mathrm{RE}$ in the industrial production processes with con-casting.

In the author's opinion, vacuum casting, vacuum arc remelting (VAR) and other non-slag and non-refractory special processes may be the reasonable techniques to apply RE in steels.

\section{Conclusions}

Made use of vacuum induction furnace to smelt test steels containing RE, studied the yield of RE and the consumption mode, such conclusions can be drawn as following:

(1) Adding RE into liquid steels in magnesia crucible, the yield of RE decreases along with the rising of RE addition amount, has no relationship with the oxygen and sulphur contents.

(2) The reaction between the liquid RE metal and the magnesia crucible is the primary RE consumption mode.

(3) Because of the RE's excessively active chemical properties, it is difficult to add RE in the industrial production processes with con-casting, adding RE in the non-slag and non-refractory special processes may be feasible.

\section{Acknowledgments}

The project was financially supported by the National Scientific Funds of Jiangsu Province (BK2011535) and the Potential Scholar Funds of Jiangsu University (10JDG037).

\section{References:}

[1] L M Wang, Q Lin, L J Yue, et al: J Alloy Compd vol. 451(2008), p. 534

[2] C Z Wang, Y B Zhang: J Chinese Soc Rare Earth vol. 30(2012), p. 530 
[3] L M Wang, Q Lin, J W Ji, et al: J Alloy Compd vol. 408-412(2006), p. 384

[4] L M Wang, X J Du, Y Gan, et al: J Rare Earth vol. 28(2010), p. 489

[5] Y B Li, F M Wang, C R Li, et al: J Univ Sci Technol B vol. 31(2009), p. 1406

[6] T D Nguyen, J Q Zhang and D J Young: Corros Sci vol. 100(2015), p. 448

[7] Y H Zhu, J Zhuang, Y S Yu, et al: J Rare Earth vol. 31(2013), p. 734

[8] J Tian, S Xue, C C Wu, et al: Corros Sci Prot Technol vol. 25(2013), p. 382

[9] L J Yue, L M Wang, J S Han: J Rare Earth vol. 28(2010), p. 952

[10] Y H Yoo, Y S Choi, J G Kim, et al: Corros Sci vol. 52(2010), p. 1123

[11] H Y Ha, C J Park and H S Kwon: Scripta Mater vol. 55(2006), p. 991

[12] B Wang, Q Y Liu, X P Mao, et al: Acta Metall Sinica vol. 44(2008), p. 863

[13] X J Du, L M Wang, L Chen, et al: Phys Examination Test vol. 27(2009), p. 8

[14] Y W Xu, S H Song and J W Wang: Mater Lett vol. 161(2015), p. 616

[15] Y Y Liu, X R Bao, L Chen, et al: J Rare Earth vol. 28(2010), p. 497

[16] L Chen, H J Long, X G Liu, et al: J Rare Earth vol. 34(2016), p. 447

[17] Y Y Zhao, J F Wang, S Zhou, et al: Mat Sci Eng A vol. 608(2014), p. 106

[18] M J Wang, Y M Li, Z X Wang, et al: J Rare Earth vol. 29(2011), p. 489

[19] X H Cui, S Q Wang, Q C Jiang,et al: J Rare Earth vol. 25(2007), p. 88

[20] L M Wang, G L Zhu, J Xu, et al: Chin Rare Earths vol. 29(2008), p. 67

[21] Y M Gao, J W Li and Z L Zhang: J Xi'an Jiaotong Univ vol. 34(2000), p. 74

[22] H G Fu, Q Xiao, J C Kuang, et al: Mat Sci Eng A vol. 466(2007), p. 160

[23] W Hua, Z H Tian and L Z Jiang: Special steel vol. 29(2008), p. 50

[24] M J Wang, L Chen, Z X Wang, et al: J Rare Earth vol. 29(2011), p. 1089

[25] M J Wang, L Chen, Z X Wang, et al: J Rare Earths vol. 30(2012), p. 84

[26] X F Zhou, X Y Yin, F Fang, et al: J Rare Earth vol. 30(2012), p. 1075

[27] L J Zhou, X Y Guo, S F Dong, et al: Shandong Metallurgy vol. 26(2004), p.40

[28] T Du, Q Y Han and C Z Wang: Physical chemistry and applications in materials of rare earths and alkaline earths (Sci Press, Beijing 1995)

[29] W C Li: Metallurgical thermodynamics (Metall Industry Press, Beijing1995)

[30] Research group of isotope, Peking Institute of Iron and Steel Technology: Acta Metall Sinica vol. 13(1977), p. 202

[31] X D Tang, W Song, H T Yang, et al: Iron Steel Vanadium Titanium vol. 22(2001), p. 68

[32] X H Li, C L Li and Y S Wang: Steelmaking vol. 19(2003), p. 38 